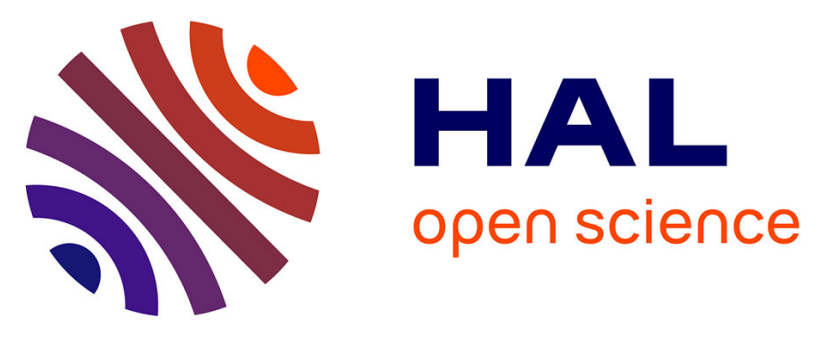

\title{
Risk factors for extensive drug resistance in multidrug-resistant tuberculosis cases: a case-case study
}

Lorenzo Guglielmetti, Nicolas Veziris, Alexandra Aubry, Florence Brossier, Christine Bernard, Wladimir Sougakoff, Vincent Jarlier, Jérôme Robert

\section{- To cite this version:}

Lorenzo Guglielmetti, Nicolas Veziris, Alexandra Aubry, Florence Brossier, Christine Bernard, et al.. Risk factors for extensive drug resistance in multidrug-resistant tuberculosis cases: a case-case study. International Journal of Tuberculosis and Lung Disease, 2018, 22 (1), pp.54-59. 10.5588/ijtld.17.0387 . hal-02968087

\section{HAL Id: hal-02968087 \\ https://hal.sorbonne-universite.fr/hal-02968087}

Submitted on 15 Oct 2020

HAL is a multi-disciplinary open access archive for the deposit and dissemination of scientific research documents, whether they are published or not. The documents may come from teaching and research institutions in France or abroad, or from public or private research centers.
L'archive ouverte pluridisciplinaire HAL, est destinée au dépôt et à la diffusion de documents scientifiques de niveau recherche, publiés ou non, émanant des établissements d'enseignement et de recherche français ou étrangers, des laboratoires publics ou privés. 


\section{Risk-factors for extensively drug resistance in multidrug-resistant tuberculosis cases: a case-case study}

\section{AUTHORS}

Lorenzo Guglielmetti ${ }^{1,2}$, Nicolas Veziris ${ }^{1,2}$, Alexandra Aubry ${ }^{1,2}$, Florence Brossier ${ }^{1,2}$, Christine Bernard ${ }^{1,2}$, Wladimir Sougakoff ${ }^{1,2}$, Vincent Jarlier ${ }^{1,2}$, and Jérôme Robert ${ }^{1,2}$, for the Laboratory Network for MDR surveillance.

\section{AFFILIATIONS}

${ }^{1}$ Sorbonne Universités, UPMC Univ Paris 06, CR7, INSERM, U1135, Centre d'Immunologie et des Maladies Infectieuses, CIMI, Team E13 (Bactériologie), Paris, France ${ }^{2}$ APHP, Centre National de Référence des Mycobactéries et de la Résistance des Mycobactéries aux Antituberculeux (CNR-MyRMA), Bactériologie-Hygiène, Hôpitaux Universitaires Pitié Salpêtrière-Charles Foix, Paris, France.

CORRESPONDING AUTHOR

Jérôme Robert, MD, PhD, MPH, Laboratoire de Bactériologie-Hygiène, Faculté de Médecine Pierre et Marie Curie (UPMC Paris 6), 91 Boulevard de l'hôpital, 75634 Paris Cedex 13, France; phone: (33) 1421620 71, fax: (33) 1421620 72; e-mail: jerome.robert@aphp.fr

\section{Running title: risk-factors for XDR-TB in France}

Wordcount: 2383 words 
Settings. Extensively drug-resistant (XDR) tuberculosis (TB) identification may be delayed because of the lack of availability of molecular testing to second-line drugs. Hence, early suspicion of XDR-TB is necessary to avoid developing further drug resistance.

Objective. We sought to identify the characteristics associated with XDR-TB among multidrug-resistant (MDR) TB cases, before the availability of second-line drug susceptibility testing (DST) results.

Methods. All MDR-TB cases with available second-line DST results recorded in France from 1998 to 2013 were classified as simple MDR (no resistance to fluoroquinolones and secondline injectables), pre-XDR (resistance to fluoroquinolones or second-line injectables), and XDR cases (resistance to both).

Results. A total of 833 MDR-TB cases were analysed, including 168 (20\%) pre-XDR and 62 (7\%) XDR-TB cases. A prior history of treatment was acknowledged for $41 \%$ of the cases, and $12 \%$ were HIV-positive. Characteristics independently associated with XDR-TB were foreign birth (odds ratio: 9.5), prior TB treatment (OR: 2.6), smear positivity (OR: 4.5), and ethambutol resistance (OR: 9.1). Characteristics independently associated with pre-XDR-TB when compared to simple MDR-TB cases were male gender (OR: 1.6), birth in Europe (OR: 2.6), and ethambutol resistance (OR: 1.9).

Conclusion. The presence of clinical or bacteriological characteristics associated with XDRTB should lead to rapid molecular testing for resistance to second-line drugs before starting a tailored treatment. 


\section{Résumé}

Cadre : L'identification des cas de tuberculose (TB) à bacilles ultra-résistants (XDR) aux antibiotiques peut être retardée par manque d'accès aux tests de sensibilité aux antituberculeux de seconde ligne (S2L). Afin de ne pas risquer d'aggraver l'étendue de la résistance, il est important d'identifier ces cas XDR sur d'autres critères.

Objectif : Identifier les caractéristiques associées à la TB XDR parmi les cas identifiés de TB à bacilles multirésistants (MDR), avant disponibilité des résultats des S2L.

Méthodes : Tous les cas de TB MDR avec des résultats de S2L diagnostiqués en France de 1998 à 2013 ont été classés en cas MDR simple (pas de résistance aux fluoroquinolones ni aux antibiotiques injectables de seconde ligne), pré-XDR (résistance à un seul de ces deux groupe d'antibiotiques), et XDR (résistance aux deux groupes d'antibiotiques).

Résultats : AU total, 833 cas de TB MDR ont été inclus dans l'analyse, dont 168 (20\%) cas pré-XDR et $62(7 \%)$ cas XDR. Des antécédents de traitement antituberculeux ont été identifiés chez $41 \%$ du total des cas et $12 \%$ étaient séropositifs pour le VIH. Les caractéristiques significativement associées à la TB XDR étaient la naissance à l'étranger (odds ratio : 9,5), les antécédents de traitements (OR : 2,6), un examen microscopique positif $(\mathrm{OR}: 4,5)$ et la résistance à l'éthambutol (OR : 9,1). Par comparaison au cas MDR simples, les caractéristiques significativement associées à la TB pré-XDR étaient le sexe masculin $(\mathrm{OR}: 1,6)$, la naissance en Europe hors de France $(\mathrm{OR}: 2,6)$ et la résistance à l'éthambutol $(\mathrm{OR}: 1,9)$.

Conclusion : Chez un malade porteur de TB MDR, la présence de caractéristiques cliniques ou bactériologiques associées à la TB XDR doit faire réaliser des S2L sans délai avant de débuter un traitement adapté individuellement. 


\section{INTRODUCTION}

France is classified as a low incidence country for tuberculosis (TB) (1). Each year approximately 6000 cases of tuberculosis are diagnosed, representing a prevalence rate of 8-9 per 100000 , and between 50 to 100 cases or $1 \%$ to $2 \%$ of the total are multidrug-resistant (MDR) (i.e., resistant to isoniazid and rifampicin). A striking increase in the number of MDRTB cases due to migration from Eastern Europe and the Caucasus has been recently reported in France (2,3), while the MDR-TB prevalence had been stable during the previous years (4). This changing epidemiology has been observed in other low-incidence countries in Western Europe, where the phenomenon poses a substantial threat to the World Health Organization (WHO) goal of TB elimination (5). It has been estimated that MDR-TB/rifampicin-resistant cases occurring in the WHO European region, mostly in its Eastern part, account for more than one fifth of the total MDR-TB/rifampicin-resistant cases estimated in the world in 2015 (1).

Among MDR-TB cases recently reported in western European countries, increasing numbers fulfil the definition of extensively drug-resistant (XDR) TB, i.e. MDR isolates with additional resistance to any fluoroquinolone and any second-line injectable drug (SLI). Despite prolonged treatment regimens, which according to WHO recommendations can exceed 20 months (6), treatment success was achieved in only $64 \%$ of MDR-TB cases in a large metaanalysis (7). The proportion of successful outcomes was lower for pre-XDR TB, defined as MDR-TB with additional resistance to any fluoroquinolone or any SLI, and further decreased to $40 \%$ for XDR-TB cases (7). Moreover, the prognosis of XDR-TB cases has been shown to be worse for patients harbouring isolates with additional resistance to other first- and secondline drugs (8). The mortality associated with XDR-TB varies according to the degree of HIV 
prevalence of the population, while in all settings a remarkable number of these subjects are

97 discharged in the community, which contributes to the spread of the disease $(9,10)$.

98 The increasing burden of XDR-TB, together with its difficult management and unsatisfactory

99 outcome, emphasizes the importance of timely diagnosis and treatment initiation for XDR-TB

100 patients. However, drug susceptibility tests (DST) are not available in all settings worldwide

101 (1). The development of automated molecular assays for DST to first line drugs may facilitate

102 the diagnosis of MDR tuberculosis but is currently not implemented for all TB cases. Rapid

103 molecular testing for second-line drugs is still restricted to selected laboratories, even in high-

104 income countries. It is therefore of interest to identify the characteristics associated with

105 additional resistance in MDR-TB patients for early recognition and better early management

106 in order to avoid increasing the initial burden of resistance. The major objective of our study

107 is to identify epidemiological and bacteriological factors associated with XDR-TB when

108 compared to non-XDR MDR-TB patients diagnosed in France. 


\section{MDR-TB surveillance in France}

113 Since 1992, the national Reference Centre for Mycobacteria (NRC) pilots a network of 250

114 laboratories, which includes all centres performing mycobacterial culture in France. Among 115 them, approximately a third are performing drug susceptibility tests (DST) for first line drugs by phenotypic methods and less than $15(6 \%)$ are using molecular biology to test for resistance to second-line drugs. Each year, the laboratories report the number of MDR-TB cases to the NRC, which confirm the MDR status and retrospectively collects additional information on MDR-TB patients by sending a standardized data collection form. Initial 120 clinical and demographical data are collected for each MDR-TB patient, including country of 121 birth, HIV status, previous TB treatment history, and microbiology. Finally, MDR Mycobacterium tuberculosis complex isolates are sent to the NRC laboratory in order to perform comprehensive DST for first and second-line anti-TB drugs. From 1992 to 2004, the

124 second-line DST were performed at either Pitié-Salpêtrière Hospital or the Pasteur Institute, 125 in Paris. Since 2005, this task was entirely taken over by the Pitié-Salpêtrière NRC. 126 Phenotypic DST for first- and second-line drugs were performed by using the proportion method on Löwenstein-Jensen medium according to WHO recommendations (11).

\section{Case-case studies}

130 Since DST for fluoroquinolones and SLI started to be routinely performed in 1998, only 131 MDR-TB cases reported from 1998 to 2013 were included in the analysis. Patients reported 132 during multiple years, i.e. culture-positive chronic cases, were considered only at the first 133 occurrence. Duplicates were eliminated before data anonymization. Patients with missing 134 DST result for fluoroquinolones and SLI were excluded from the analysis. 
In order to compare characteristics of MDR-TB patients harbouring different resistance patterns to fluoroquinolones and SLI, we performed different nested case-case studies within

137 the cohort. In the main analysis, patients harbouring XDR isolates were compared to all the

138 other cases harbouring non-XDR MDR isolates. Two other case-case analyses were

139 conducted, comparing i) cases with pre-XDR isolates to those harbouring MDR isolates with

140 no additional resistance to any fluoroquinolone and any SLI (defined as simple-MDR), and ii)

141 XDR to pre-XDR patients.

\section{Data analysis}

144 Medians with interquartile ranges (IQR) were calculated for continuous variables, and

145 frequency distributions were tabulated for categorical variables. Groups were compared using

146 the two-sample Wilcoxon-Mann-Whitney test for continuous data and Fisher's exact test for

147 categorical data. In order to assess the independent association of predictive variables, logistic

148 regression modelling was performed. For each case-case analysis, variables associated to a

149 group of patients under a cut-off of $\mathrm{p}$-value $<0.2$ in univariate analysis were added to a

150 multivariable model. The variables of resistance to ethambutol and streptomycin were

151 considered for multivariable analysis, as they could be of interest to predict additional

152 resistance in MDR-TB cases. Pyrazinamide DST status was not included because of the

153 difficulty to interpret its result and consequently a high number of missing data. Patients with

154 unknown HIV status were considered as HIV-negative and patients with unknown place of

155 birth were classified as foreign-born. With regard to the other variables, patients with missing

156 data were excluded from the analysis. Backward selection procedure was performed, with age

157 and sex included by default in all models. The foreign-born status or WHO regions of birth

158 were tested alternatively in the models. Birth in France was considered as the reference in all

159 models. The best-fitted model was chosen on the basis of epidemiological and statistical 
160 criteria, such as the Hosmer-Lemeshow goodness-of-fit test and the Akaike Information

161 Criterion. Interaction terms were included in the models and dropped if non-significant. Only

162 the model with the least number of variables is reported for each case-case analysis. Odds

163 ratios $(\mathrm{OR})$ were calculated with their $95 \%$ confidence intervals $(\mathrm{CI}) . \mathrm{P}$-values $<0.05$ were

164 considered as statistically significant. STATA, version 11.1 (StataCorp, College Station,

165 Texas, USA) was used for statistical analysis.

166

167 Ethics

168 Data were routinely collected during standard care and abstracted from medical files. No

169 personal identifiers were recorded. Therefore, according to French regulations, the study did 170 not require institutional review board or patients' approvals. 
173 Overall, 983 MDR-TB cases have been recorded in France during the 16-year study period, 174 ranging from 31 to 91 per year. Among them, 93 (9.5\%) cases were discarded because of 175 duplicate declarations and $57(5.8 \%)$ because DST results were not available (Figure 1). The 176 baseline characteristics of the 833 MDR-TB patients finally included in the study are shown

177 in Table 1. Patients were mostly male (64\%), born in Sub-Saharan Africa (30\%) or in 178 European countries excluding France (28\%). Among the latter, a large majority of patients 179 (91\%) were from the 18 high-priority countries (HPC) identified by WHO Regional Office 180 for Europe's Stop TB Strategy.

181 French-born patients accounted for only $15 \%$ of the cases, and the country of birth was 182 unknown for $23(2.8 \%)$ patients. A majority of patients had pulmonary TB (90\%), and 56\% 183 had positive sputum-smear examination. A total of $41 \%$ had a prior history for TB treatment. 184 A total of $12 \%$ were HIV-positive, $76 \%$ HIV-negative, and $12 \%$ had unknown HIV status. 185 The median age at diagnosis was 32 years (IQR: 25-43).

186 A total of $603(72 \%)$ patients had isolates susceptible to both fluoroquinolones and SLI, 168 187 (20\%) pre-XDR isolates, and $62(7 \%)$ XDR isolates. Additional resistance was frequent for 188 streptomycin (69\%) and ethambutol (47\%).

190 Comparison of XDR-TB cases to all other MDR-TB cases

191 When comparing the 62 XDR-TB to the 771 non-XDR MDR-TB cases, XDR-TB was 192 associated with an age at diagnosis of 35 to 44 years (Table 1). XDR-TB patients were 193 significantly more likely to be born outside France and particularly in Europe (OR: 35.6; 95\% 194 CI 13.9-91.6), to have a prior history of TB treatment (OR: 3.7; 2.0-6.9), and to be sputum smear-positive (OR: 3.5 ; 1.8-6.9). No significant association was observed with sex, disease 
196 localisation and HIV status. XDR isolates were significantly more likely to harbour resistance

197 to streptomycin and ethambutol (Table 1).

198 After multivariable logistic regression analysis, foreign birth (OR 9.5; CI: 1.2-75.9), sputum

199 smear positivity (OR 4.5; CI: 2.0-10.1), prior TB treatment (OR 2.6; CI: 1.4-5.0), and 200 resistance to ethambutol (OR 9.1; CI: 4.0-20.7) remained independently associated with the 201 risk of XDR-TB (Tables 2, model 1). When replacing foreign birth by regions of birth in a 202 second model (Table 2, model 2), birth in the WHO European region (OR 21.0; CI: 7.0-63.1) 203 was significantly associated with XDR-TB, while no other region of birth remained 204 associated with XDR-TB status.

\section{Comparison of pre-XDR TB cases to simple-MDR-TB cases}

In univariate analysis, pre-XDR TB cases were significantly more likely than simple-MDR TB cases to be male, born in the European region, born in Africa excluding the Sub-Saharan region, to have prior $\mathrm{TB}$ treatment and to harbour isolates with additional resistance to ethambutol and streptomycin (data not shown). In multivariable analysis, characteristics significantly associated with pre-XDR TB as compared to simple-MDR TB were male gender (OR 1.6; CI: 1.0-2.6), birth in Europe (OR 2.6; CI: 1.3-5.1), and ethambutol resistance (OR 1.9; CI: 1.4-2.7) (Table 3, model 1).

\section{Comparison of pre-XDR TB cases to XDR-TB cases}

216 In univariate analysis, XDR-TB cases were significantly more likely than pre-XDR TB cases to be born in the European region, or in Africa excluding the Sub-Saharan region, to have a positive sputum smear examination, to have prior TB treatment, and to harbour isolates with additional resistance to ethambutol (data not shown). In multivariable analysis, characteristics remaining significantly associated with XDR-TB as compared to pre-XDR TB were birth in 
221 Europe (OR 8.1; CI: 3.1-21.3), sputum smear positivity (OR 5.2; CI: 2.9-9.3), and ethambutol

222 resistance (OR 3.9; CI: 1.7-8.8) (Table 3, model 2).

223 
We compared the characteristics of patients diagnosed with MDR-TB or XDR-TB over 16 years in France. The results of our study delineate a few characteristics associated with resistance beyond MDR.

First, foreign birth was associated with XDR-TB, and with higher resistance in both 230 intermediate steps between MDR-TB and XDR-TB. In low TB incidence countries, the 231 predominance of foreign-born patients among MDR-TB cases is a common finding (12-15).

232 In our study, the highest risk group was those of patients born in countries with high 233 incidence of MDR/XDR-TB, such as European HPC. This phenomenon has been previously 234 described in a country-wide cohort of TB patients in Canada (16). Second, our results have 235 shown that previous TB treatment was significantly associated with XDR-TB. This is a wellknown risk factor, which has already been described in different settings in association with both MDR-TB (17-20) and XDR-TB (21-24). Third, smear positivity was also independently associated with XDR-TB in our cohort, in the comparison with both MDR-TB and pre-XDR TB strains. This could be linked to the fact that most XDR-TB patients in our cohort had a 240 long previous treatment histories and advanced pulmonary lesions. This finding, however, is not confirmed by other similar studies $(24,25)$. This may also reflect high bacterial load, 242 which is directly linked to a higher likelihood of resistant mutants in the lesions. Fourth, 243 XDR-TB cases were associated with significantly higher rates of ethambutol resistance, and 244 the same finding was reported for more resistant strains in both intermediate analyses. Higher 245 rates of ethambutol resistance have been consistently reported in XDR-TB patients $246(10,26,27)$, and may have been a facilitating factor for the progressive selection of resistance 247 to second-line drugs. Hence, rapid availability of ethambutol DST could help in the 248 management of MDR-TB patients. However, the performance of the first version of the most 
commonly used line probe assay for the detection of resistance to second-line drugs was

250 suboptimal for ethambutol, probably due to the lack of testing in regions outside $e m b B$ codon

251306 (28). Unfortunately, the second version of this test does not include ethambutol testing at

252 all.

253 In addition, male sex was linked to pre-XDR TB when compared to MDR-TB, as previously

254 reported in a study in the Russian Federation (21), but in contrast to a multicentre study where

255 female sex was linked to XDR-TB (24). Finally, we did not find a significant association

256 between XDR-TB and HIV infection, in concordance with a large study including countries

257 with variable HIV burden (24). In contrast, a link between HIV and XDR-TB has been shown

258 in a high-incidence country like South Africa (17).

259 Our study has some limitations. Risk factors that have been consistently described in 260 literature, such as alcohol and drug abuse, history of imprisonment, and previous treatment 261 with second-line drugs, were not captured in the routine data collection form and therefore not 262 analysed in our study. In addition, the epidemiological changes that occurred in the MDR-TB 263 population in France over time (2) could have influenced our findings, and only a small 264 proportion (7\%) of patients included in the study were XDR-TB. However, both these secular 265 trends and the low rates of XDR-TB cases are common to most low-incidence countries (29), 266 and therefore do not affect the generalizability of our results to these settings. Finally, a 267 limited number of patients had missing data for the key variables (HIV status and country of 268 birth), which were managed by making assumptions.

In conclusion, we identified factors associated with XDR-TB among patients diagnosed with

272 suspicion for XDR-TB among MDR-TB cases and warrant testing with rapid molecular 273 assays for second-line drugs. Indeed, a new version of a line probe assay has been shown to 
274 be improved (30) and has recently been endorsed by the WHO (31). The combination of 275 implementing rapid diagnostic tools and identifying high-risk groups may lead to promptly 276 detect XDR-TB cases and to design effective empirical regimens while waiting for 277 comprehensive DST results. Finally, new shorter MDR-TB treatment regimens should be 278 avoided in patients harbouring such characteristics. 
Table 1. Characteristics of 833 multidrug-resistant tuberculosis (MDR-TB) cases according to 281 extensively drug-resistant (XDR-TB) status.

\begin{tabular}{|c|c|c|c|c|c|}
\hline \multirow[b]{2}{*}{ Categorical variables } & \multirow{2}{*}{$\begin{array}{c}\text { All cases } \\
\begin{array}{c}(n=833) \\
n(\%)\end{array}\end{array}$} & \multicolumn{2}{|c|}{ XDR-TB isolates } & \multirow{2}{*}{$\begin{array}{c}\text { OR } \\
(\mathrm{CI} 95 \%)\end{array}$} & \multirow[t]{2}{*}{$\mathbf{p}$} \\
\hline & & $\begin{array}{c}\text { Yes } \\
(n=62) \\
n(\%)\end{array}$ & $\begin{array}{c}\text { No } \\
(n=771) \\
n(\%)\end{array}$ & & \\
\hline Sex Male & $533(64)$ & $45(74)$ & $488(64)$ & $1.6(0.8-2.9)$ & 0.16 \\
\hline \multicolumn{6}{|l|}{ Age*: $^{*}$} \\
\hline$\leq 14$ & $26(3)$ & $1(2)$ & $25(3)$ & 1 & \\
\hline $15-24$ & $167(20)$ & $9(14)$ & $158(20)$ & $1.4(0.5-4.0)$ & 0.51 \\
\hline $25-34$ & $298(36)$ & $19(31)$ & $279(36)$ & $1.7(0.7-4.2)$ & 0.25 \\
\hline $35-44$ & $165(20)$ & $21(34)$ & $144(19)$ & $3.6(1.5-8.7)$ & $<0.01$ \\
\hline $45-64$ & $133(16)$ & $10(16)$ & $123(16)$ & $2.0(0.6-6.4)$ & 0.23 \\
\hline$\geq 65$ & $38(5)$ & $2(3)$ & $36(5)$ & $1.4(0.3-5.4)$ & 0.64 \\
\hline Foreign-birth or unknown country* & $710(85)$ & $61(98)$ & $649(84)$ & $11.5(4.2-31.6)$ & 0.001 \\
\hline \multicolumn{6}{|l|}{ Region of birth*: } \\
\hline France & $123(15)$ & $1(2)$ & $122(16)$ & 1 & - \\
\hline Europe (France excluded) & $230(28)$ & $52(84)$ & $178(24)$ & $35.6(13.9-91.6)$ & $<0.001$ \\
\hline North Africa & $97(12)$ & $4(6)$ & $93(12)$ & $5.2(0.9-30.4)$ & 0.06 \\
\hline Sub-Saharan Africa & $252(30)$ & $3(5)$ & $249(33)$ & $1.5(0.3-6.3)$ & 0.61 \\
\hline Others & $108(13)$ & $2(3)$ & $106(14)$ & $2.3(0.6-9.2)$ & 0.24 \\
\hline Pulmonary tuberculosis & 747 (90) & $60(97)$ & $687(90)$ & $3.3(1.1-10.1)$ & 0.11 \\
\hline Smear positive for pulmonary cases & $464(56)$ & $51(82)$ & $413(57)$ & $3.5(1.8-6.9)$ & $<0.001$ \\
\hline HIV-positive* & $101(12)$ & $4(6)$ & $97(13)$ & $0.5(0.1-2.0)$ & 0.22 \\
\hline Prior tuberculosis treatment & $343(41)$ & $43(73)$ & $300(42)$ & $3.7(2.0-6.9)$ & $<0.001$ \\
\hline \multicolumn{6}{|l|}{ Resistance to: } \\
\hline Ethambutol & $389(47)$ & $55(89)$ & $334(44)$ & $10.2(3.6-28.9)$ & $<0.001$ \\
\hline Streptomycin & 577 (69) & $53(85)$ & $524(69)$ & $2.6(1.3-5.3)$ & 0.006 \\
\hline
\end{tabular}

282 OR, odds ratio; CI, confidence interval

$283 * 6$ patients with missing age, 23 with unknown region of birth, and 97 with unknown HIV status 
Table 2. Multivariable logistic regression analysis assessing characteristics associated with extensively drug-resistant tuberculosis in a cohort of multidrug-resistant tuberculosis cases. The country of birth of patients was entered into the model after categorization according to foreign-born versus French-born (Model 1) or according to the birth in the European region versus birth outside the European region and French-born (Model 2). The European region was defined according to the World Health Organisation; France was excluded from this group.

\begin{tabular}{|l|c|c|c|c|}
\hline \multirow{2}{*}{ Categorical variables } & \multicolumn{2}{|c|}{ Model 1 } & \multicolumn{2}{c|}{ Model 2 } \\
\cline { 2 - 5 } & $\begin{array}{c}\text { OR } \\
(\text { CI 95\%) }\end{array}$ & & $\begin{array}{c}\text { OR } \\
(\text { CI 95\%) }\end{array}$ & \\
\hline Foreign birth & $9.5(1.2-75.9)$ & 0.034 & - & \\
\hline $\begin{array}{l}\text { Born in the European region } \\
\text { (France excluded) }\end{array}$ & - & & $21.0(7.0-63.1)$ & $<0.001$ \\
\hline Sputum smear-positivity & $4.5(2.0-10.1)$ & $<0.001$ & $3.8(2.1-6.8)$ & $<0.001$ \\
\hline Prior tuberculosis treatment & $2.6(1.4-5.0)$ & 0.004 & $2.2(1.2-3.9)$ & 0.018 \\
\hline Additional resistance to ethambutol & $9.1(4.0-20.7)$ & $<0.001$ & $6.1(2.3-16.4)$ & $<0.001$ \\
\hline OR, odds ratio; CI, confidence interval. & & & \\
\hline
\end{tabular}


294 Table 3. Multivariable logistic regression analysis assessing characteristics associated with 295 tuberculosis (TB) due to multidrug-resistant (MDR) isolates with additional resistance to any 296 fluoroquinolone or any second-line injectable drug (pre-XDR) as compared to MDR-TB with no 297 additional resistance to any fluoroquinolone or second-line injectable drug (Model 1) and 298 characteristics associated with extensively drug-resistant TB as compared to Pre-XDR TB (Model 2).

299 The European region was defined according to the World Health Organisation; France was excluded 300 from this group and included as itself in the models.

\begin{tabular}{|l|c|c|c|c|}
\hline \multirow{2}{*}{ Categorical variables } & \multicolumn{2}{|c|}{ Model 1 } & \multicolumn{2}{c|}{ Model 2 } \\
& \multicolumn{2}{|c|}{ ODR-TB vs. pre-XDR TB } & \multicolumn{2}{c|}{ pre-XDR TB vs. XDR-TB } \\
\cline { 2 - 5 } & $($ IC 95\%) & & OR & (IC 95\%) \\
\hline Sex, male & $1.6(1.0-2.6)$ & 0.033 & - & \\
\hline $\begin{array}{l}\text { Born in the European region (France } \\
\text { excluded) }\end{array}$ & $2.6(1.3-5.1)$ & 0.006 & $8.1(3.1-21.3)$ & $<0.001$ \\
\hline $\begin{array}{l}\text { Sputum smear-positive pulmonary } \\
\text { tuberculosis }\end{array}$ & - & & $5.2(2.9-9.3)$ & $<0.001$ \\
\hline $\begin{array}{l}\text { Strain with additional resistance to } \\
\text { Ethambutol }\end{array}$ & $1.9(1.4-2.7)$ & $<0.001$ & $3.9(1.7-8.8)$ & $<0.001$ \\
\hline CI, confidence interval; OR, odds ratio. & & & & \\
\hline
\end{tabular}




\section{ACKNOWLEDGEMENTS}

307 The authors thank all microbiologists that participated in the NRC Laboratory Network for MDR-TB

308 surveillance and Cristina Gutierrez for data checking during the 1998-2004 period.

309 We are also thankful to the clinicians who shared information.

310

311 JR conceived and designed the study

312 LG \& JR performed the statistical analysis, analysed the results and drafted the manuscript

$313 \mathrm{LG}, \mathrm{NV}, \mathrm{AA}, \mathrm{FB}, \mathrm{CB}, \mathrm{WS}, \mathrm{VJ} \& \mathrm{JR}$ collected the data, participated in the interpretation of the results,

314 and critically revised the manuscript.

315 NV, AA, FB, CB \& WS were in charge of drug susceptibility tests.

316 All authors gave final approval of the current version to be published 


\section{BIBLIOGRAPHY}

1. WHO. Global tuberculosis report 2016. WHO Geneva Switz. 2016;WHO/HTM/TB/2014.13.

2. Bernard C, Brossier F, Sougakoff W, Veziris N, Frechet-Jachym M, Metivier N, et al. A surge of MDR and XDR tuberculosis in France among patients born in the Former Soviet Union. Euro Surveill Bull Eur Sur Mal Transm Eur Commun Dis Bull. 2013;18:33.

3. Guglielmetti L, Le Du D, Jachym M, Henry B, Martin D, Caumes E, et al. Compassionate Use of Bedaquiline for the Treatment of Multidrug-Resistant and Extensively Drug-Resistant Tuberculosis: Interim Analysis of a French Cohort. Clin Infect Dis. 2015 Jan 15;60(2):188-94.

4. Robert J, Trystram D, Truffot-Pernot C, Jarlier V. Multidrug-resistant tuberculosis: eight years of surveillance in France. Eur Respir J. 2003 Nov 1;22(5):833-7.

5. Falzon D, Zellweger J-P, Migliori GB, Jaramillo E. Drug resistance and tuberculosis elimination in low-incidence countries. Eur Respir J. 2014 Dec 1;44(6):1408-11.

6. World Health Organization. WHO treatment guidelines for drug-resistant tuberculosis, 2016 update [accessed on 2017 July 24]. Available from: http://www.who.int/tb/areas-of-work/drugresistanttb/MDRTBguidelines2016.pdf

7. Falzon D, Gandhi N, Migliori GB, Sotgiu G, Cox HS, Holtz TH, et al. Resistance to fluoroquinolones and second-line injectable drugs: impact on multidrug-resistant TB outcomes. Eur Respir J. 2012 Oct 25;42(1):156-68.

8. Migliori GB, Sotgiu G, Gandhi NR, Falzon D, DeRiemer K, Centis R, et al. Drug resistance beyond extensively drug-resistant tuberculosis: individual patient data meta-analysis. Eur Respir J. 2012 Oct 11;42(1):169-79.

9. Pietersen E, Ignatius E, Streicher EM, Mastrapa B, Padanilam X, Pooran A, et al. Long-term outcomes of patients with extensively drug-resistant tuberculosis in South Africa: a cohort study. The Lancet [Internet]. 2014 Jan [cited 2014 Feb 5]; Available from: 
10. Keshavjee S, Gelmanova IY, Farmer PE, Mishustin SP, Strelis AK, Andreev YG, et al. Treatment of extensively drug-resistant tuberculosis in Tomsk, Russia: a retrospective cohort study. The Lancet. 2008;372(9647):1403-1409.

11. WHO. Guidelines for Surveillance of Drug Resistance in tuberculosis. 2nd Edition. Geneva, WHO, 2003.

12. Eker B, Ortmann J, Migliori GB, Sotgiu G, Muetterlein R, Centis R, et al. Multidrug- and Extensively Drug-Resistant Tuberculosis, Germany. Emerg Infect Dis. 2008 Nov;14(11):1700-6.

13. Schecter GF, Scott C, True L, Raftery A, Flood J, Mase S. Linezolid in the Treatment of Multidrug-Resistant Tuberculosis. Clin Infect Dis. 2010 Jan;50(1):49-55.

14. Anderson L, Tamne S, Watson J, Cohen T, Mitnick C, Brown T, et al. Treatment outcome of multidrug resistant tuberculosis in the United Kingdom: retrospective-prospective cohort study from 2004 to 2007. Euro Surveill Bull Eur Sur Mal Transm Eur Commun Dis Bull. 2013;18(40):pii=20601.

15. van Altena R, de Vries G, Haar CH, de Lange WCM, Magis-Escurra C, van den Hof S, et al. Highly successful treatment outcome of multidrug-resistant tuberculosis in the Netherlands, 20002009. Int J Tuberc Lung Dis. 2015 Apr 1;19(4):406-12.

16. Minion J, Gallant V, Wolfe J, Jamieson F, Long R. Multidrug and Extensively Drug-resistant Tuberculosis in Canada 1997-2008: Demographic and Disease Characteristics. Sola C, editor. PLoS ONE. 2013 Jan 9;8(1):e53466.

17. Andrews JR, Shah NS, Weissman D, Moll AP, Friedland G, Gandhi NR. Predictors of Multidrugand Extensively Drug-Resistant Tuberculosis in a High HIV Prevalence Community. Tyagi AK, editor. PLoS ONE. 2010 Dec 29;5(12):e15735.

18. Vashakidze L, Salakala A, Shubladze N, Cynamon M, Barbakadze K, Kikvidze M, et al. Prevalence and risk factors for drug resistance among hospitalized tuberculosis patients in Georgia. Int J Tuberc Lung Dis. 2009;13(9):1148-53. 
19. Skrahina A, Hurevich H, Zalutskaya A, Sahalchyk E, Astrauko A, van Gemert W, et al. Alarming levels of drug-resistant tuberculosis in Belarus: results of a survey in Minsk. Eur Respir J. 2012 Jun;39(6):1425-31.

20. Liang L, Wu Q, Gao L, Hao Y, Liu C, Xie Y, et al. Factors contributing to the high prevalence of multidrug-resistant tuberculosis: a study from China. Thorax. 2012;67(7):632-638.

21. Shin SS, Keshavjee S, Gelmanova IY, Atwood S, Franke MF, Mishustin SP, et al. Development of Extensively Drug-resistant Tuberculosis during Multidrug-resistant Tuberculosis Treatment. Am J Respir Crit Care Med. 2010 Aug;182(3):426-32.

22. Kliiman K, Altraja A. Predictors of Extensively Drug-Resistant Pulmonary Tuberculosis. Ann Intern Med. 2009 Jun 2;150(11):766-75.

23. Jeon CY, Hwang SH, Min JH, Prevots DR, Goldfeder LC, Lee H, et al. Extensively Drug-Resistant Tuberculosis in South Korea: Risk Factors and Treatment Outcomes among Patients at a Tertiary Referral Hospital. Clin Infect Dis. 2008 Jan 1;46(1):42-9.

24. Dalton T, Cegielski P, Akksilp S, Asencios L, Caoili JC, Cho S-N, et al. Prevalence of and risk factors for resistance to second-line drugs in people with multidrug-resistant tuberculosis in eight countries: a prospective cohort study. The Lancet. 2012;380(9851):1406-1417.

25. Balabanova Y, Radiulyte B, Davidaviciene E, Hooper R, Ignatyeva O, Nikolayevskyy V, et al. Risk factors for drug-resistant tuberculosis patients in Lithuania, 2002-2008. Eur Respir J. 2012 May 1;39(5):1266-9.

26. Mitnick CD, Shin SS, Seung KJ, Rich ML, Atwood SS, Furin JJ, et al. Comprehensive treatment of extensively drug-resistant tuberculosis. N Engl J Med. 2008;359(6):563-574.

27. Günther G, van Leth F, Alexandru S, Altet N, Avsar K, Bang D, et al. Multidrug-Resistant Tuberculosis in Europe, 2010-2011. Emerg Infect Dis. 2015 Mar;21(3):409-16.

28. Brossier F, Sougakoff W, Bernard C, Petrou M, Adeyema K, Pham A, et al. Molecular Analysis of the embCAB Locus and embR Gene Involved in Ethambutol Resistance in Clinical Isolates of Mycobacterium tuberculosis in France. Antimicrob Agents Chemother. 2015 Aug;59(8):4800-8. 
29. European Centre for Disease Prevention and Control/WHO Regional Office for Europe.

397 Tuberculosis surveillance and monitoring in Europe 2016. Stockholm: European Centre for $398 \quad$ Disease Prevention and Control, 2016.

399 30. Brossier F, Guindo D, Pham A, Reibel F, Sougakoff W, Veziris N, et al. Performance of the New 400 Version (v2.0) of the GenoType MTBDR s/ Test for Detection of Resistance to Second-Line Drugs in Multidrug-Resistant Mycobacterium tuberculosis Complex Strains. Land GA, editor. J Clin Microbiol. 2016 Jun;54(6):1573-80.

403 31. WHO. The use of molecular line probe assays for the detection of mutations associated with 404 resistance to fluoroquinolones (FQs) and second-line injectable drugs (SLIDs): policy guidance. 405 WHO Geneva Switz. 2016;WHO/HTM/TB/2016.07. 